\title{
Personality Antecedents of Self-Other Rating Discrepancy
}

\section{La Personalidad como Antecedente de la Discrepancia Autovaloraciones-Valoraciones de Otros}

\author{
Nila Sinha \\ Assess Systems-A Bigby HavisCompany \\ Jessica Mesmer-Magnus \\ University of North Carolina Wilmington
}

\author{
Chockalingam Viswesvaran \\ Florida International University
}

\begin{abstract}
Multi-rater feedback systems are increasingly being used in organizations for assessment and development. Research suggests self-ratings are often uncorrelated with other-ratings, which has implications for ratee receptivity to feedback. Prior research suggests ratee personality may offer insight into selfother rating discrepancy. We explored the extent to which five work-related personality dimensions offer explanatory variance in self-other rating discrepancy using archival data of 527 employees from a large financial organization. Analyses of 487 self-peer dyads and 501 self-supervisor dyads revealed low agreement among self-, supervisor-, and peer-ratings of performance. Self-raters high on extraversion, dominance, cultural conformity, cynicism, and detail orientation were somewhat likely to over-rate their performance as compared to peer ratings. Cynical and detail-oriented raters were likely to over-rate their performance as compared with supervisor ratings. Detail orientation and cultural conformity interacted to predict self-other rating discrepancies for both supervisors and peers. Implications for research and practice are discussed.
\end{abstract}

Keywords: self-other rating discrepancy, rater personality, supervisor/peer ratings, 360-feedback.

\begin{abstract}
Resumen. En los últimos tiempos, se está incrementando el uso de sistemas de feedback multi-evaluador por parte de las organizaciones para la evaluación y el desarrollo de su personal. La investigación sugiere que las autoevaluaciones del desempeño a menudo no correlacionan con las evaluaciones de los demás, lo que tiene implicaciones para la receptividad del evaluado al feedback. La investigación previa sugiere que la personalidad del evaluado puede ser un punto importante en la discrepancia entre las autoevaluaciones y las evaluaciones de los otros. En el presente estudio se exploró el grado en que cinco dimensiones de personalidad relacionadas con el trabajo explican la varianza en la discrepancia entre las autoevaluaciones y las evaluaciones de los otros, usando los datos de archivo de 527 empleados de una gran organización financiera. El análisis de 487 parejas de autoevaluaciones y evaluaciones de los compañeros y 501 parejas de autoevaluaciones y evaluaciones de los supervisores reveló un bajo acuerdo entre las autoevaluaciones, las evaluaciones de los supervisores y las evaluaciones de los compañeros. Los evaluados altos en extraversión, dominancia, conformidad cultural, cinismo y orientación al detalle fueron algo más probables a sobre-estimar su desempeño en las autoevaluaciones comparadas con las evaluaciones que recibían de sus compañeros. Los evaluados cínicos y orientados al detalle tendieron a sobre-estimar su desempeño en comparación con las evaluaciones de sus supervisores. La orientación al detalle y la conformidad cultural interactuaron para predecir las discrepancias entre las autoevaluaciones y las evaluaciones de los supervisores y los compañeros. Finalmente, se discuten las implicaciones para la investigación y la práctica profesional de estos hallazgos.

Palabras clave: discrepancia autoevaluaciones-evaluaciones de los otros, personalidad del evaluador, evaluaciones de los supervisores y compañeros, feedback 360.
\end{abstract}

Multi-rater performance evaluations (like 360degree feedback) are increasing in popularity as organizations are realizing the benefits of triangulating performance data by gathering different perspectives (Conway, Lombardo, \& Sanders, 2001; Van Hooft, Van Der Flier, \& Minne, 2006). Interestingly, research results obtained from such instruments has substantiated Thornton's (1980) observation that "individuals have a significantly different view of their own job

Please address correspondence regarding this manuscript to Jessica Mesmer-Magnus at the University of North Carolina Wilmington, 601 South College Road, Wilmington, NC 28403 USA; magnusj@uncw.edu. performance than that held by other people" (Harris \& Schaubroeck, 1988, p. 43). In fact, although rating discrepancies may occur between any two raters in the 360 process, the most striking of these discrepancies tends to exist between self-ratings and ratings provided by other sources (e.g., supervisor, peer; Thornton, 1980; Wohlers \& London, 1989). In fact, prior research has estimated self-other ratings correlations to be lower than .20 (Atwater \& Yammarino, 1992; Carless, Mann, \& Wearing, 1998; Conway \& Huffcutt, 1997; Schmitt, Ford, \& Stults, 1986). Rating discrepancy can have negative consequences to employee satisfaction and performance (Bono \& Colbert, 2005), and negative implications for the validity of performance 
appraisal instruments (Facteau \& Craig, 2001; Murphy \& DeShon, 2000).

What factors relate to self-other rating discrepancy? Prior research has explored a variety of factors which may predict rating discrepancy, including biographical characteristics, cognitive processes, contextual factors and job-related experiences (Yammarino \& Atwater, 1997). Self-rater personality is an underexplored factor with the potential to offer unique insight into rating discrepancies (Goffin \& Anderson, 2006; Yammarino \& Atwater, 1997). Further, researchers have argued that an understanding of the personality characteristics that contribute to and/or correlate with inflated self-ratings would potentially enable greater value to be derived from developmental feedback sessions, particularly when these sessions are held with raters prone to inflated self-ratings (Brett \& Atwater, 2001; Goffin \& Anderson, 2006; Sosik \& Godshalk, 2004).

In this study, we explore the role of five specific workrelated personality characteristics of the self-rater (extraversion, dominance, cultural conformity, cynicism, and detail orientation) in predicting self-peer and self-supervisor rating discrepancy. We focus on the personality of the self-rater rather than that of other-raters for several reasons. First, in multi-rater performance instruments, personality idiosyncrasies of other raters are likely to be averaged out. Second, prior research suggests the discrepancy between self and peer/supervisor performance ratings is greater than that between peers and supervisors, suggesting the self-rater's personality may explain unique variance (Conway \& Huffcutt, 1997; Facteau \& Craig, 2001; Harris \& Schaubroeck, 1988). Third, attribution theory and the actor-observer bias (Jones \& Harris, 1967; Jones \& Nisbett, 1971) suggest self-raters are more likely than other-raters to attribute poor performance to situational/external factors rather than internal factors. Due to the underlying mechanisms associated with these attributions, the self-rater personality is the most relevant focus.

\section{Importance of Investigating Determinants of Self- Other Rating Discrepancy}

Research suggests self-other rating discrepancy may presage certain work outcomes for the rater; the nature of these outcomes differs depending on whether the rater tended to over-estimate, under-estimate, or accurately estimate their performance in relation to others' ratings (Sosik \& Godshalk, 2004; Yammarino \& Atwater, 1997). The most negative outcomes are associated with over-estimators. Over-estimators are thought to provide inaccurate ratings because they are ignorant to what others think of them (which is reinforced by the well-known tendency for managers to avoid the discomfort associated with giving accurate/clear negative feedback) and because they tend to discount negative feedback while accepting positive feedback as both accurate and informational (Yammarino \& Atwater, 1997). According to Yammarino \& Atwater (1997), these individuals tend to (1) have an unclear perception of their own strengths and weaknesses, (2) have negative attitudes (e.g., hostility and resentment), (3) not see the need for training and development thus suffering from career derailment, and (4) have high absenteeism, low organizational commitment, high turnover, and frequent conflict with coworkers. Although they are unlikely to see behavior change as necessary, they have the most to gain from developmental feedback offered by multirater performance systems, and when feedback is carefully provided (e.g., via one-on-one performance review sessions, with a clear developmental plan in place, and tailored to their needs), they may be willing to take steps to improve their performance (Yammarino \& Atwater, 1997).

Negative consequences may also occur when individuals underrate themselves in comparison with ratings provided by others. Specifically, these individuals tend to have an unclear idea of their own strengths/weaknesses, set low aspiration levels, underachieve, and make ineffective job-relevant decisions (Yammarino \& Atwater, 1997). Johnson and Ferstl (1999) found that under-estimators' performance actually tended to decline following performance feedback, suggesting it is particularly important to effectively manage the feedback/development process with these individuals. Self-consistency theory would suggest this occurs because the individual works to change their behavior to be more consistent with internal evaluations (Johnson \& Ferstl, 1999; Korman, 1970, 1976). Importantly, if given the opportunity, they tend to engage in effective behaviors as mentors and leaders in mentor-protégé and supervisor/subordinate relationships (Sosik \& Godshalk, 2004).

\section{Self-Other Ratings in Multi-Rater Feedback}

Compared with other evaluative techniques, 360degree evaluation provides a comprehensive picture of individual job effectiveness by gathering information from all vital stakeholders in the workplace. Unlike other performance evaluation methods, 360-degree feedback makes individuals accountable to coworkers, customers, and subordinates as well as supervisors because they know that these individuals will be providing input on performance evaluations. Further, although supervisor evaluations are commonly used performance indicators, these tools raise validity concerns when the supervisor is unable to routinely observe employee job performance, does not adequately understand the employee's job, or is prone to rating bias/error (Harris \& Schraubroeck, 1988; Landy \& Farr, 1980; Mount, 1998; Sosik \& Godshalk, 2004). Such concerns are underscored by meta-analytic research which has found the 
average correlation between two managers' performance evaluations of a ratee to be only .50-.52, between two peers to be only .37-.46, and between two direct reports to be only .30 (Conway \& Huffcutt, 1997; Viswesvaran, Ones, \& Schmidt, 1996).

A number of factors may account for disagreement among raters. For example, Harris and Schaubroeck (1988) suggested egocentric biases of the self-rater and differences in organizational level and observational opportunities of other-raters may explain some disagreement. Others argue rating discrepancy is due to either an inherent difference in psychological processing between actors (self-raters) and observers (otherraters; Farh \& Dobbins, 1989; Jones \& Nisbett, 1971) or raters focusing on different aspects of work performance associated with their unique perspectives (Farh \& Dobbins, 1989; Klimoski \& London, 1974; Murphy \& DeShon, 2000).

Yammarino and Atwater (1997) found self-raters provided more consistent ratings with other-raters when they were higher in cognitive ability, had a greater ability to process information, better memory capacity, and were more mentally stable. Research also suggests females tend to be more accurate in their selfratings of performance and more open to feedback than males (Atwater \& Yammarino, 1997; Roberts, 1991; Wohlers \& London, 1989); individuals with greater tenure at an organization tend to be less accurate in their ratings and less likely to seek feedback than individuals who more recently joined the organization (Ashford, 1989; Levine, Flory \& Ash, 1977); and individuals in supervisory or leadership positions tend to rate themselves more similarly to others' ratings than non-leaders/supervisors (Gallo \& McClintock, 1962). In line with social attribution theory, research by Ashford (1989), Harris and Schaubroeack (1988) and Jones and Nisbett (1971) suggests self-raters who believe failure was due to circumstances beyond their control will likely adjust their self-evaluation accordingly whereas other-raters are less likely to make this same adjustment. Others have found that individuals may be more likely to provide accurate self-ratings when they know their ratings will be confirmed using objective data (Schlenker, Weingold, \& Hallam, 1990), the rating scales provide clear anchors for ratings (Ashford, 1989; Wohlers \& London, 1989), and they have experience providing self-ratings (Levine, Flory, $\&$ Ash, 1977). Previous experience with success/failure and positive/negative feedback from the job also tends to affect the accuracy of self-ratings (Atwater \& Yammarino, 1997; Fry, 1976; Swann, 1983).

\section{Personality Characteristics Potentially Associated with Self-Other Rating Discrepancy}

Research suggests rater personality characteristics are also a likely underlying factor associated with rat- ing (Campbell, 1993; Goffin \& Anderson, 2006: Yammarino \& Atwater, 1997). Like personality, rating tendencies tend to be stable across time (Campbell, 1993), suggesting some stable, underlying factor contributes to self-rating. Bernardin, Cooke and Villanova (2000) found that raters who were both agreeable and less conscientious made the most lenient ratings. Atwater and Yammarino (1997) cite several personality factors which may be related to rating consensus, including locus of control, self-esteem, and depression. Seaman (1963) found individuals with an internal locus of control were more likely to have self-assessments aligned with viewpoints of others and were more likely to retain performance information. Similarly, high self-esteem individuals are more likely to provide accurate ratings and seek feedback than low self-esteem individuals (Kernis, 1991). Goffin and Anderson (2006) found need for achievement and selfesteem were associated with self-other rating discrepancies resulting from self-rating inflation, and anxiety was associated with self-supervisor rating discrepancy resulting from self-rating deflation. We explore the role of five work-related personality dimensions often assessed as a part of 360 evaluation in self-other rating discrepancy: extraversion, dominance, cultural conformity, cynicism, and detail orientation.

Extraversion. Extraverted individuals tend to seek out and feel comfortable in social situations whereas individuals high on introversion tend to relish solitude and be less interested in spending time with others. Yammarino and Atwater (1993) found extraversion influenced an individual's self-perception; similarly, Farmer, Jarvis, Berent, and Corbett (2001) found extraversion predicted an individual's self-esteem. Checcino's (1997) study of 194 middle school students found extraverted students provided higher self-evaluations of school performance than introverted students, though there was no difference in actual performance levels across the two groups. Visser, Ashton, and Vernon (2008) found most individuals tended to overestimate their own intelligence, but this was particularly true of extraverted individuals. Wymer and Penner's (1985) experiments on undergraduate psychology students were relevant to rating congruence in that they found introverts knew themselves better than extraverts because they spent more time in self-reflection; as such, they provided more accurate self-ratings. In their study of student leaders at the US Naval Academy, Roush and Atwater (1992) also found individuals high on introversion provided performance ratings better aligned with those provided by their subordinates. Meleddu and Guicciardi (1998) found extraverted individuals tend to provide more socially desirable ratings. In the context of 360 performance evaluation, an extraverted individual may be inclined to provide high self-ratings of performance as these may be seen as more socially desirable than lower ratings. Given these findings, we expect: 
Hypothesis 1: Individuals high on extraversion will be more likely to over-estimate their own performance as compared with supervisor-and peer-ratings than individuals low on extraversion.

Dominance. Individuals high in dominance are characterized as enjoying the act of exerting control. An exploratory study using the California Personality Inventory found that the scale of dominance predicted differences in supervisor self-ratings and ratings provided by others on a multi-rater performance instrument (Brutus, Fleenor, \& McCauley, 1999). Brutus et al. (1999) suggest that dominance influences how individuals evaluate their own behavior and leadership, and this evaluation biases self-ratings. Research following the Social Relations Model (Kenney, 1994) suggests individuals high in dominance may have a stronger sense of self and be less likely to incorporate others' views into their self-concept (Swann \& Pelham, 1990). As such, their self-ratings are less likely to agree with those of others. Research in cognitive, personality, and clinical psychology also supports the idea that individuals high in dominance tend to inflate self-ratings of various performance and personality characteristics compared to ratings provided by others (Barbaree \& Davis, 1984; Djikic, Chan, \& Peterson, 2007; Leising, Rehbein, \& Sporberg, 2006). As such, we expect:

Hypothesis 2: Individuals high on dominance will be more likely to over-estimate their own performance as compared with supervisor-and peer-ratings than individuals low on dominance.

Cultural conformity. Cultural conformity refers to the extent to which an individual believes in and is concerned with adhering to the values and practices of one's work group/organization; low scores on this dimension reflect individualism whereas high scores reflect collectivism. Paquet (2005) found collectivists were more prone to rating inaccuracy than individualists. Similarly, Fadil (1997) found collectivists were less concerned with establishing performance differentiation among peers, tending to rate similarly and reward equally across members of their team. As collectivists tend to have higher expectations for and evaluations of performance than individualists (Sosik \& Jung, 2002), they may inflate performance evaluations of others; since they tend to fail to differentiate among performance of team members, this over-estimation of performance may translate to inflated self-ratings as well. Finally, researchers have found that individualists tend to objectively outperform collectivists (Sosik \& Jung, 2002; Waldman, Atwater, \& Davidson, 2004), though collectivists tended to provide higher selfevaluations than individualists (Sosik \& Jung, 2002). As such, we expect:
Hypothesis 3: Individuals high on cultural conformity (collectivists) will be more likely to over-estimate their own performance as compared with supervisorand peer-ratings than individuals low on cultural conformity (individualists).

Cynicism. Little research has been conducted on the role of cynicism in rating accuracy; however, findings from prior research may offer insight to this relationship. For example, in their study of 110 police officers, Regoli, Crank, and Rivera (1990) found cynical officers had poorer performance across all indicators than their peers. As many individuals tend to over-rate their performance (e.g., Visser et al., 2008), this suggests cynical individuals may be more prone to self-other rating discrepancy than non-cynical individuals. Treynor (2004) found cynical individuals tended to believe others engaged in unethical acts and used this belief as justification for doing so themselves.

In a performance evaluation context, cynical individuals may be inclined to provide inflated ratings because they believe others are doing so and they want to be compared favorably to others. In their study of full-time employees in the government and private sectors, Bryne and Hochwarter (2008) found cynical employees tended to react more negatively to managerial support than less cynical employees because they tended to misinterpret the managers' motivations. In a 360 -feedback context, a cynical employee may perceive the manager's/organization's intent in conducting the evaluation in a negative light (e.g., believing it is a means to provide non-constructive negative feedback or build a case for an unwanted personnel action), which may affect self-ratings. McGivern and Ferlie (2007) found cynical professionals were more likely to perceive performance appraisals to be a waste of time. In a 360-feedback appraisal, cynical employees may be disinterested in the process/feedback and thus give little thought to their self-ratings. Given these findings, we would expect:

Hypothesis 4: Individuals high on cynicism will be more likely to over-estimate their own performance as compared with supervisor-and peer-ratings than less cynical individuals.

Detail orientation. Research in rating ability has also investigated the role of analytic ability and detail interest. For example, in their study of university students and hospital employees, Gruenfeld and Arbuthnot (1969) found participants who were distracted by irrelevant stimuli were less likely to be able to distinguish characteristics and performance among others. Findings suggest that an individual's ability to focus on only selected, relevant details is related to self-other rating agreement. Likewise, Borman (1979) found high detail orientation resulted in rater accuracy in evaluations of others' performance. 
Hypothesis 5: Individuals low on detail orientation will be more likely to over-estimate their own performance as compared with supervisor-and peer-ratings than individuals higher in detail orientation.

An interesting interaction between detail orientation and cultural conformity is also probable such that the greatest discrepancies in self-other ratings may be found between raters when the self-rater is (1) high on cultural conformity (collectivist) and low on detail orientation or (2) low on cultural conformity (individualist) and high on detail orientation; importantly, the reasons behind these discrepancies would differ. As mentioned above, collectivists are more prone to self-inflation of ratings than are individualists (Sosik \& Jung, 2002; Waldman et al., 2004). Combine that tendency with low detail orientation (which may make the individual less able to objectively and accurately evaluate their own performance; e.g., Gruenfeld \& Arbuthnot, 1969) and the result is likely self-ratings that are greatly inflated compared to other-ratings. In this case, the self-other rating discrepancy is due at least in part to the inaccuracy of the self-rater. On the other hand, individualists tend to objectively outperform collectivists (Sosik \& Jung, 2002); an individualist high on detail orientation may describe an individual who not only outperforms others, but is also able to better track details associated with performance episodes and hence provide more accurate performance ratings. In this case, self-other rating discrepancy would result at least in part from less accurate ratings on the part of the other rater. As such, we expect that:

Hypothesis 6: Detail orientation and cultural conformity will interact to predict self-other rating discrepancy such that discrepancies will be greatest when individuals are high on cultural conformity and low on detail orientation and low on cultural conformity and high on detail orientation.

\section{Method}

\section{Participants}

This study made use of an archival database of 527 employees of a large international financial organization specializing in credit cards, auto/home/medical loans, insurance, and investments. The database included employee personality assessment data and performance ratings collected as part of a firm-wide organizational leadership development program. Participants in this program were representatives from management within the sales, finance, human resources, information technology, legal, marketing, and operations departments. All participants held professional/managerial-level positions requiring a minimum of 2 years of college education. Seventy percent of the sample was Caucasian, $54 \%$ was male, and $67 \%$ were between the ages of 21 and 39, with the majority falling in the upper half of that range. Data collection yielded self-to-peer data of 487 dyads and self-tosupervisor data of 501 dyads. Performance ratings provided for participants were composed of an average of two to four peer raters and one to two supervisors per participant.

\section{Measures}

The database includes (1) employee self-ratings of personality and demographic characteristics, and (2) employee self-ratings as well as peer- and supervisorratings of each employee's performance.

Personality assessment. The focal dimensions of personality (extraversion, dominance, cultural conformity, cynicism, and detail orientation) were measured using the ASSESS instrument which was developed by organizational psychologists for use in consulting within a business arena. This instrument assesses narrow work-related personality dimensions which have been found most useful for training and development in applied settings. The ASSESS instrument was adapted in 1970 from two personality tools widely used in the occupational setting: the Dynamic Factors Opinion Survey (DFOS) and the Guilford-Zimmerman Temperament Scale (GZTS). Despite alterations, it correlates .85-.90 with the DFOS and the GZTS. Based on a normative sample of 30,000 , the average reliability estimate for the ASSESS instrument is .77, which is comparable with the reliabilities of other personality tests (cf. Viswesvaran \& Ones, 1999). Although the ASSESS instrument measures 20 dimensions of personality relevant to the thinking, working and relating aspects of the work context, we analyzed only the five dimensions relevant to our hypotheses and the available extant literature.

Extraversion was assessed using the sociability subscale of the ASSESS instrument. This scale assesses the extent to which the individual seeks out and feels comfortable in social situations. Dominance was assessed using the assertiveness subscale. This scale assesses the extent to which an individual enjoys the act of exerting control, tends to impose their sense of self on others, and the likelihood they will be influenced by others. The cultural conformity subscale assesses the extent to which one believes in and is concerned with adhering to the values and practices of one's peers and organization. Low scores indicate individualism whereas high scores indicate a more collectivist orientation. Cynicism was assessed using of the 'positive about people' subscale. This scale assesses the individual's tendency to be trusting and optimistic in his/her outlook toward other people. Scale items were reverse-scored such that higher scores indicated cynicism whereas lower scores indicated a likelihood of focusing on positive facets in 
others. Detail orientation indicates a preference for work which requires attention to fine detail. Low scores indicate a dislike for activities that require exactness/precision whereas high scores indicate preference for highly detailed work.

Performance. Performance was assessed using a customized multi-rater instrument which permits ratings of performance by self, peers, and supervisors. Performance ratings were made along various dimensions found to be relevant to the focal organization, including evaluating to what extent the individual was able to work/communicate/collaborate effectively with others, seek out business opportunities, stay focused and organized, and take leadership roles involved with recruiting and motivating talent. Raters scored employee performance on a scale from 1 (minimal/ infrequent demonstration of behaviors) to 5 (regular/ effective demonstration of behaviors). Factor analyses did not support the existence of multiple performance factors, so we collapsed across items to compute an overall indicator of performance.

\section{Procedure}

All data were collected via an online format over a three-month period. Participants were selected by the human resources department at the focal organization based on efforts for succession planning as well as individual requests for professional development. Supervisors and co-workers of these participants were identified and invited to complete the performance instrument. Participants completed the personality and performance instruments concurrently. Thus, the data was collected with the purpose of linking personality traits to the performance indicators/competencies to help employees identify their developmental needs. All participants and raters were informed both of the purpose of the rating process and how the feedback would be utilized. To enhance the construct validity of the performance instrument, all raters were trained on the rating process. Raters were instructed to be as forthright and candid as possible, and, except in the cases where supervisors provided the ratings, raters were assured no organizational member would be privy to their direct responses (ratings were only provided to participants if three or more responses were received to maintain confidentiality). Security of all information was maintained through the use of personalized access codes allocated through email; further, the data was held off-site with a consulting firm external to the organization.

\section{Data Analysis}

Rating agreement/discrepancy was accomplished through the computation of difference scores.
Specifically, the difference between self-peer and selfsupervisor performance ratings was computed such that a positive difference indicated the employee rated themselves higher than his/her supervisor/peer and a negative difference indicated the employee rated themselves lower than his/her supervisor/peer. This difference was correlated with the focal self-rated personality dimensions. Significant correlations indicate this personality dimension is predictive of over- and/or under-rating tendency.

Hierarchical multiple regression analyses were performed to test the interaction hypothesis. Here, supervisor/peer performance ratings were regressed on control variables, self-rated performance, cultural conformity, detail orientation, and the interaction term. In step one, employee sex, age, and race were entered as control variables. In the second step, self-rated performance, cultural conformity, and detail orientation were entered. In the third step, the interaction term representing the product of cultural conformity and detail orientation was entered. Significant interactions were plotted to permit interpretation of the nature of the interaction relative to the hypothesis.

\section{Results}

Tables 1-3 report the results of correlational analyses used to test the study hypotheses 1-5 and to explore the role of personality in self and other performance ratings. Table 1 provides a summary of the correlations among self-ratings of the focal personality dimensions. Extraversion was positively related to dominance $(r=$ $.44, p<.05)$ and negatively related to cynicism $(r=$ $-.19, p<.05)$. Cultural conformity was positively related to both cynicism $(r=.26, p<.05)$ and detail orientation $(r=.26, p<.05)$. Cynicism was also negatively related to dominance $(r=-.09, p<.05)$.

Table 1. Correlations among Self-Ratings of Personality Dimensions

\begin{tabular}{lccccc}
\hline & 1 & 2 & 3 & 4 & 5 \\
\hline Extraversion & $(.85)$ & & & & \\
Dominance & $.44^{*}$ & $(.64)$ & & & \\
Cultural Conformity & .01 & -.01 & $(.58)$ & & \\
Cynicism & $-.19^{*}$ & $-.09^{*}$ & $.26^{*}$ & $(.61)$ & \\
Detail Orientation & .04 & -.03 & $.26^{*}$ & -.03 & $(.64)$ \\
\hline
\end{tabular}

Note. $n=497$; Scale reliabilities for the current sample are reported on the diagonal; * indicates correlation is significant at the $p<.05$ level.

Table 2 reports the correlations among self, supervisor, and peer performance ratings. Our results are consistent with prior research suggesting low agreement among these three rating sources. The correlation between self and supervisor performance ratings was only .14 $(p<.05)$. The correlation between self- and peer-ratings was even lower at .05 $(p>.05)$. Supervisors and peers had greater agreement, but the 
Table 2. Correlations among Self, Supervisor, and Peer Overall Performance Ratings

\begin{tabular}{lcc}
\hline & 1 & 2 \\
\hline Self-Rated Performance & - & \\
Supervisor-Rated Performance & $.14^{*}$ & - \\
Peer-Rated Performance & .05 & $.30 *$ \\
\hline
\end{tabular}

Note. * indicates correlation is significant at the $p<.05$ level.

correlation between their ratings was still only .30 $(p<.05)$.

Table 3 reports correlations between participant personality and self-, supervisor-, and peer-performance ratings, as well as the correlations relevant to hypotheses 1-5 wherein personality is correlated with selfother rating discrepancies. (Positive correlations indicate the individual rated themselves higher than their supervisor/peer; negative correlations indicate the individual rated themselves lower than their supervisor/peer.) All five self-rated personality dimensions are positively correlated with self-ratings of performance. The strongest correlations are seen with cultural conformity (collectivism; $r=.17, p<.05$ ), detail orientation $(r=.19, p<.05)$, and dominance $(r=.13, p<.05)$. Interestingly, participant/self personality had little to do with supervisor and peer ratings of performance. The exception was with dominance, where dominant individuals were likely to get lower performance ratings from their peers.

Hypothesis 1 predicted extraverted individuals would be more likely to over-estimate their performance when compared with supervisor/peer ratings than less extraverted individuals. Results partially support this hypothesis. Specifically, although extraversion was positively correlated with self-rated performance (as seen in Table 3), extraversion was not correlated with self-supervisor difference scores. Extraversion was, however, positively correlated with self-peer difference scores, indicating extraverted individuals tend to over-estimate their performance when compared with their peers' evaluations $(r=.10, p<.05)$.

Hypothesis 2 predicted dominant individuals would be more likely to over-estimate their performance when compared with supervisor/peer ratings than less dominant individuals. Results partially support this hypothesis. Although dominance was associated with higher self-ratings of performance, it was not significantly associated with self-supervisor difference scores. However, like extraversion, dominance was positively correlated with self-peer rating discrepancies $(r=.18, p<.05)$, suggesting dominant individuals tend to over-estimate their performance in the eyes of their peers.

Hypothesis 3 predicted individuals high on cultural conformity (collectivists) would be more likely to over-estimate their performance when compared with supervisor/peer ratings than individuals scoring low on cultural conformity. Results partially support this hypothesis. Cultural conformity was associated with higher self-ratings of performance, and was positively correlated with self-peer rating discrepancies $(r=.14$, $p<.05)$. Cultural conformity was not correlated with self-supervisor rating discrepancies.

Hypothesis 4 predicted cynical individuals would be more likely to over-estimate their performance when compared with supervisor/peer ratings than less cynical individuals. Results support this hypothesis. Cynicism was associated with both higher self-ratings of performance and self-other rating discrepancies $(r=$ .12 for both self/supervisor and self/peer; $p<.05$ ).

Hypothesis 5 predicted individuals low on detail orientation would be more likely to over-estimate their performance than individuals high on detail orientation. Results suggest the relationship is actually opposite that predicted. Specifically, detail orientation was associated with higher self-reports of performance and over-estimates of performance ratings when compared with both self-supervisor and self-peer rating discrepancies $(r=.10$ and .10 , respectively; $p<.05)$.

Table 4 and Figure 1 report results relevant to Hypothesis 6, which predicted an interaction between cultural conformity and detail orientation in predicting self-other rating discrepancies. Hierarchical multiple regressions provide support for Hypothesis 6. Specifically, the interaction between cultural conformity and detail orientation explained significant variance in the difference between self-supervisor $(\beta=-.71, p<$ $.01)$ and self-peer performance ratings $(\beta=-.63, p<$ $.01)$. Plots of the interactions support the nature of the

Table 3. Correlations between personality dimensions and performance ratings and rating discrepancies

\begin{tabular}{lccccc}
\hline & $\begin{array}{c}\text { Self-Rated } \\
\text { Performance }\end{array}$ & $\begin{array}{c}\text { Supervisor-Rated } \\
\text { Performance }\end{array}$ & $\begin{array}{c}\text { Self-Supervisor } \\
\text { Rating Discrepancy }\end{array}$ & $\begin{array}{c}\text { Peer-Rated } \\
\text { Performance }\end{array}$ & $\begin{array}{c}\text { Self-Peer Rating } \\
\text { Discrepancy }\end{array}$ \\
\hline Extraversion & $.09^{*}$ & .05 & .00 & -.04 & $.13^{*}$ \\
Dominance & $.13^{*}$ & .00 & .08 & .00 & $.18^{*}$ \\
Cultural Conformity & $.17^{*}$ & .07 & .07 &. .07 & $.12^{*}$ \\
Cynicism & $.09^{*}$ & -.05 & $.09^{*}$ & .08 & $.12^{*}$ \\
Detail Orientation & $.19^{*}$ & .05 & & $.10^{*}$ \\
\hline
\end{tabular}

Note. $\mathrm{n}=452-516 ; *$ indicates correlation is significant at the $p<.05$ level. 
Table 4. Hierarchical multiple regression analyses predicting self-other rating discrepancies from detail orientation and cultural conformity

\begin{tabular}{|c|c|c|c|c|c|c|}
\hline \multirow[b]{2}{*}{ Predictor } & \multicolumn{3}{|c|}{ Supervisor-Rated Performance } & \multicolumn{3}{|c|}{ Peer-Rated Performance } \\
\hline & Step 1 & Step 2 & Step 3 & Step 1 & Step 2 & Step 3 \\
\hline $\begin{array}{l}\text { Age } \\
\text { Sex } \\
\text { Race } \\
\text { Self-Rated Performance } \\
\text { Cultural Conformity } \\
\text { Detail Orientation } \\
\text { Cultural Conformity x } \\
\text { Detail Orientation }\end{array}$ & $\begin{array}{r}-.09 \\
.07 \\
-.04\end{array}$ & $\begin{array}{l}-.08 \\
.08 \\
-.03 \\
.12^{*} \\
.06 \\
-.01 \\
-.71 * *\end{array}$ & $\begin{array}{l}-.08 \\
.07 \\
-.04 \\
.12 * \\
.46 * * \\
.47 * *\end{array}$ & $\begin{array}{l}-.20 * * \\
.06 \\
-.06\end{array}$ & $\begin{array}{l}-.20 * * \\
.06 \\
-.07 \\
.07 \\
-.04 \\
.04 \\
-.63 * *\end{array}$ & $\begin{array}{c}-.21 * * \\
.05 \\
-.07 \\
.07 \\
.31 * \\
.46^{*} *\end{array}$ \\
\hline $\begin{array}{l}\mathrm{R}^{2} \\
\text { Total } \mathrm{R}^{2} \\
n\end{array}$ & $\begin{array}{r}.01 \\
.01 \\
414\end{array}$ & $\begin{array}{l}.02 * \\
.03 *\end{array}$ & $\begin{array}{l}.02 * * \\
.05 * *\end{array}$ & $\begin{array}{l}.05 * * \\
.05 * * \\
420\end{array}$ & $\begin{array}{l}.01 \\
.05^{* *}\end{array}$ & $\begin{array}{l}.02 * * \\
.07 * *\end{array}$ \\
\hline
\end{tabular}

Note. Standardized Betas are listed.

$* p<.05 . * * p<.01$

predicted interaction: self-other rating discrepancies were greatest when the self-rater was (1) high on cultural conformity and low on detail orientation or (2) low on cultural conformity and high on detail orientation.

\section{Discussion}

To echo Thornton's (1980) statement regarding selfother rating discrepancy, we don't often see ourselves the way others see us. In fact, we often see ourselves in a better light than others see us, in part because we may see the bigger picture associated with why/how we have succeeded/failed (actor/observer bias) and in part due to other factors. In many ways this egoistic bias is beneficial as it helps us maintain our self-esteem and confidence. However, when it prevents us from ade- quately diagnosing our strengths and weaknesses, it may curb our capacity to perform and our ability to develop to reach our potential. The main goal of most multi-rater performance evaluation systems is to provide constructive developmental feedback to individuals by offering various perspectives on the individuals' effectiveness in a number of work-related competencies. Self-ratings are often used as a baseline in 360degree feedback - a place to begin discussions of strengths and weaknesses during the developmental feedback system. When self- and other-ratings are in agreement, the discussion and development plan are more easily navigated (Facteau, Facteau, Russell, \& Poteet, 1998). However, when the individuals' ratings are different than those provided by others, they may be caught off guard by the less favorable impressions held by those around them or they may discount evaluations they don't feel they deserve (Facteau et al.,

Figure 1. Nature of interaction between cultural conformity and detail orientation in predicting self-other rating discrepancies

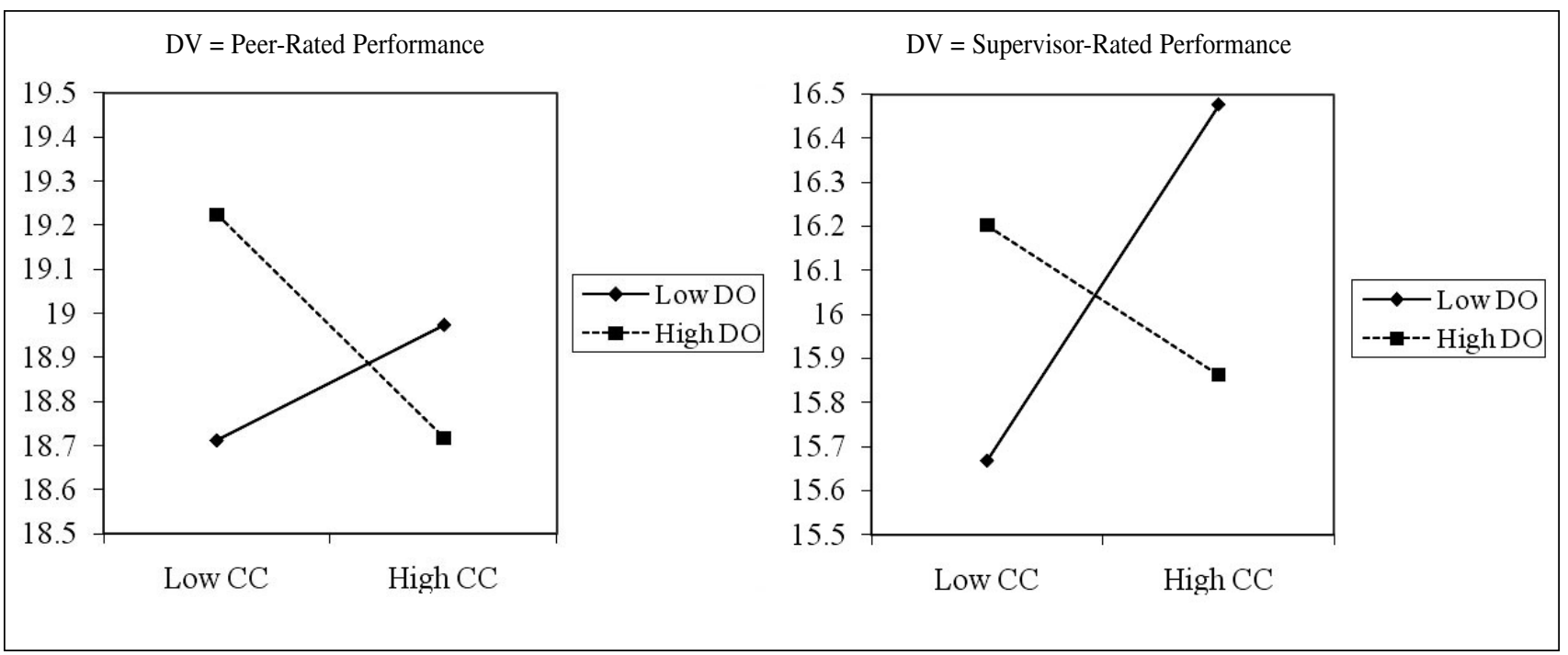


1998; Goffin \& Anderson, 2006). Understanding factors which are associated with and/or lead to self-other rating discrepancy may improve the potential multirater developmental feedback can be effective.

In this study, we explored the extent to which five work-related personality dimensions were associated with self-other rating discrepancy in multi-rater performance assessments. Results suggest a personality basis to self and other performance ratings as well as self-other rating discrepancy. Specifically, a rater's extraversion, dominance, cultural conformity, cynicism, and detail orientation were positively related to self-ratings of performance. As expected, these personality dimensions also explained some variance in selfother rating differences, such that individuals high on these personality factors were likely to overrate their performance in comparison with evaluations provided by peers, and cynical and detail-oriented raters were likely to overrate their own performance in comparison with supervisor ratings.

As predicted, cultural conformity and detail orientation interacted to predict self-peer and self-supervisor rating discrepancies. Past research suggested that detail-oriented individuals would be better able to provide accurate ratings than less detail-oriented individuals because they would be able to attend to only relevant aspects of performance (Borman, 1979; Gruenfeld \& Arbthnot, 1969). Although results of bivariate correlations between detail-orientation and self-other rating discrepancies suggested the opposite is true (individuals high on detail orientation were more likely to provide high self-ratings of performance compared to ratings by supervisors/peers), results of hierarchical multiple regressions suggest the interaction between cultural conformity and detail-orientation offers a bigger picture. Specifically, detail-oriented individuals who were low in cultural conformity and individuals low on detail-orientation but high on cultural conformity were likely to provide higher self-ratings than those provided by others. Given past research which points to an objective difference in individualists' and collectivists' performance wherein individualists tend to outperform collectivists (e.g., Waldman et al., 2004) and collectivists' tendency to inflate ratings (e.g., Sosik \& Jung, 2002), it is likely that detail orientation offers additional insight into rating discrepancies for individualists/collectivists. Individuals high on detail orientation, for example, may keep a more detailed mental record of their previous performance episodes (as well as aspects of those episodes which may have led to success/failure) giving them more to draw from when making self-evaluations of performance. When a detail-oriented individual is high in individualism, they may objectively outperform others and be better prepared to accurately rate their own performance than would other raters, resulting in selfother rating discrepancies driven, at least in part, by other-rater inaccuracy. However, when a collectivist is low on detail orientation, they are likely more prone to inflated ratings based on only a general egoistic picture of their performance, resulting in self-other rating discrepancies driven, at least in part, by self-rater inaccuracy.

It was interesting to note that although an individual's personality affects their own self-evaluations, it does not necessarily influence supervisor performance ratings and largely is irrelevant to peer-ratings. The exception for peer-ratings was with dominance; specifically, all things being equal, peers tended to rate the performance of their dominant coworkers lower than less dominant coworkers. This may be a function of the peer's previous experience with the individual they are rating. Kenney (1994) found dominant individuals were less likely than less dominant individuals to incorporate others' feedback into their self-concept and subsequent behavior. If the peer had provided feedback to the individual in the past and felt they did not give adequate weight to their suggestions, they may feel the need to be harsher in providing feedback in the future as a means of getting the individual to pay attention to their advice. Alternatively, it may be that the dominant individual's behavior pattern is counterproductive to interpersonal interactions with peers in the workplace, negatively affecting peer evaluations of performance. Another noteworthy finding was the low intercorrelations among self, supervisor, and peer performance ratings. The correlation between self and supervisor performance ratings was only .14; the correlation between self and peer performance ratings was non-significant and near zero. In fact, supervisors and peers had greater agreement than either of these pairings. These results suggest that regardless of personality predictors, self-ratings of performance will likely be off the mark, placing the onus on the facilitator of the 360degree feedback to orient the individual around others' perceptions of strengths and weaknesses and to build the developmental plan accordingly. Although our results suggest these personality dimensions may shed some light on self-other rating discrepancies and provide some insight in how to proceed with developmental feedback sessions, the potential for individuals to be surprised (pleasantly or not) by the content of their multi-rater performance review is widespread.

\section{Limitations and Directions for Future Research}

One potential limitation of our study is that our sample consisted of individuals engaged in a leadership development program, which implies a certain amount of pre-selection (and thus potential range restriction on performance) which may skew the results. Importantly, if performance was subject to range restriction, then our results may actually under-estimate the role of personality factors in performance ratings. Further, the data was collected for developmental rather than 
administrative purposes, which may have influenced the ratings provided by each constituent group. That is, rating tendencies, biases, and errors are likely to differ depending on the circumstances in which the ratings are gathered.

Second, the sample was drawn from the private sector (financial industry) which raises a generalizability concern. Specifically, Brutus, Fleenor, and London (1998) found differences in rating agreement across private versus public sectors. Specifically, they found employees in public sector organizations tended to under-rate themselves whereas employees in private sector organizations tended to over-rate their own performance. As such, caution should be used when generalizing the results of our study to public sector employees.

Future research might also explore the role of personality in self-other rating discrepancies for other constituent groups (e.g., direct reports and customers). The importance of rating consistency across self-other dyads differs depending on the individual's job, organizational needs, constituent power/importance relevant to the individual's job performance, etc. As such, understanding the role of personality in both pieces of the rating dyad can help in customizing feedback and training for such considerations. Similarly, future research might also examine personality of 'other' raters in addition to the 'self' rater. Perhaps understanding personality similarities and differences among sources as they relate to rating tendencies will offer a more complete understanding of self-other agreement.

\section{Practical Implications}

The aim of this research was to explore the link between personality and rating tendencies and selfother agreement. Cronbach and Snow (1977) argued the necessity of considering the "characteristics that people bring to the training environment as essential ingredients of the instructional design system" ( $p$. 184). An understanding of the role of personality in self-rating tendencies and self-other agreement can be used to enhance the benefits of the developmental feedback process as well as the success of coaching efforts. The current study suggests certain personality dimensions are associated with self-perceptions of performance and with the extent to which individuals' ratings agree with those provided by supervisors and peers. A practical implication for coaching/feedback sessions is that performance feedback and associated training can be tailored specifically to the needs of the individual so as to maximize the potential feedback will be digested, accepted and utilized. Ward (1995) argues, "Some people receive uncomfortable surprises when they get their feedback and, as there are many ways to avoid or rationalize unacceptable data, the par- ticipant might need help to learn from the information" (p. 20). In other words, exploring the relationship between personality and rating tendencies provides valuable insights towards maximizing receptivity in professional development sessions which can help improve performance and enhance communication between employees and team members, supervisors, and organizational stakeholders (DeNisi \& Kluger, 2000; Harris \& Schaubroeck, 1988). For example, dominant self-raters might be clued into the potential their behavior pattern has an unwanted negative effect on peer perceptions of their performance. Coaches might help the individual explore how their personality trait manifests itself in interactions with peers to ensure the positive aspects of this trait are not overshadowed by perceived negative aspects.

In conclusion, the results of the current study serve as a beginning for understanding the personality antecedents of self-other agreement. Rater personality offers explanatory variance in self-ratings of performance. Further, the work-related dimensions examined here offer some insight into the self-other rating discrepancies, particularly within the self-peer dyad. With the increasing use of team-based work in organizations, bridging the gap between self and peer expectations and evaluations is becoming increasingly important. Research and practice in the areas of training and development associated with human resource applications of multi-rater feedback systems will benefit from the continued investigation of the role of personality in rating tendencies and agreement.

\section{References}

Ashford, S. J. (1989). Self-assessments in organizations: A literature review and integrative model. In L. L. Cummings \& B. M. Staw (Eds.), Research in Organizational Behavior (vol. 11, pp. 133-174.). Greenwich, CT: JAI Press.

Atwater, L. E. \& Yammarino, F. (1992). Does self-other agreement on leadership perceptions moderate the validity of leadership and performance predictions? Personnel Psychology, 45, 141-164.

Atwater, L. E. \& Yammarino, F. (1997). Self-other rating agreement: A review and model. In G. Ferris (ed.), Research in Personnel and Human Resource Management, (vol. 15, pp. 121-174). Greenwich CT: JAI Press.

Barbaree, H. E. \& Davis, R. B. (1984). Assertive behavior, self-expectations, and self-evaluations in mildly depressed university women. Cognitive Therapy and Research, 8, 153-171.

Bernardin, H. J., Cooke, D. K., \& Villanova, P. (2000). Conscientiousness and agreeableness as predictors of rating leniency. Journal of Applied Psychology, 85, 232-236.

Bono, J. E. \& Colbert, A. E. (2005). Understanding responses to multi-source feedback: the role of core self-evaluations. Personnel Psychology, 58, 171-203. 
Borman, W. C. (1979). Individual difference correlates of accuracy in evaluating others' performance effectiveness. Applied Psychological Measurement, 3, 103-115.

Brett, J. F. \& Atwater, L. E. (2001). 360 feedback: Accuracy, reactions, and perceptions of usefulness. Journal of Applied Psychology, 86, 930-942.

Brutus, S., Fleenor, J. W., \& London, M. (1998). Does 360degree feedback work in different industries? A between industry comparison of the reliability and validity of multi-source performance ratings. Journal of Management Development, 17, 177-190.

Brutus, S., Fleenor, J. W., \& McCauley, C. D. (1999). Demographic and personality predictors of congruence in multi-source ratings. Journal of Management Development, 18, 417-435.

Carless, S. A., Mann, L., \& Wearing, A. J. (1998). Leadership, managerial performance, and 360-degree feedback. Applied Psychology: An International Review, 47, 481-496.

Checcino, D. J. (1997). Relationships among personality type, self-concept, grade point average and gender of seventh graders. An unpublished doctoral dissertation.

Conway, J. M. \& Huffcut, A. I. (1997). Psychometric properties of multisource performance ratings: A meta-analysis of subordinate, supervisor, peer and self-ratings. Human Performance, 10, 331-360.

Conway, J. M., Lombardo, K., \& Sanders, K. C. (2001). A meta-analysis of incremental validity and nomological networks for subordinate and peer ratings. Human Performance, 14, 267-303.

Cronbach, L. J. \& Snow, R. E. (1977). Aptitude and instructional methods. New York: Wiley.

DeNisi, A. S. \& Kluger, A. N. (2000). Feedback effectiveness: Can 360-degree appraisals be improved? Academy of Management Executive, 14, 129-139.

Djikic, M., Chan, I., \& Peterson, J. B. (2007). Reducing memory distortions in egoistic self-enhancers: Effects of indirect social facilitation. Personality and Individual Differences, 42, 723-731.

Facteau, J. D. \& Craig, S. B. (2001). Are performance appraisal ratings from different rating sources comparable? Journal of Applied Psychology, 86, 215-227.

Facteau, C. L., Facteau, J. D., Russell, J. E., \& Poteet, M. L. (1998). Reactions of leaders to 360-degree feedback from subordinates and peers. The Leadership Quarterly, 9, 427-448.

Fadil, P. A. (1997). An empirical investigation of the influences of individualism/collectivism, recipient group membership, and recipient performance differentiation on reward behavior in third person allocation situations. An unpublished doctoral dissertation.

Farh, J. H. \& Dobbins, G. H. (1989). Effects of self-esteem on leniency bias in self-reports of performance: A structural equation model analysis. Personnel Psychology, 42, 835-850.

Farmer, R. F., Jarvis, L. L., Berent, M. K., \& Corbett, A. (2001). Contributions to global self-esteem: The role of importance attached to self-concepts associated with the five factor model. Journal of Research in Personality, 35, 483-499.

Fry, P. (1976). Success, failure, and self-assessment ratings. Journal of Consulting and Clinical Psychology, 44, 413-419.

Gallo, P. \& McClintock, C. (1962). Behavioral, attitudinal, and perceptual difference between leaders and non-leaders in situations of group support and non-support. Journal of Social Psychology, 56, 121-133.

Goffin, R. D. \& Anderson, D. W. (2006). The self-rater's personality and self-other disagreement in multi-source ratings: Is disagreement healthy? Journal of Managerial Psychology, 22, 271-289.

Gruenfeld, L. \& Arbuthnot, J. (1969). Field independence as a conceptual framework for prediction of variability in ratings of others. Perceptual and Motor Skills, 28, 31-44.

Harris, M. \& Schaubroeck, J. (1988). A meta-analysis of self-supervisor, self-peer, and peer-supervisor ratings. Personnel Psychology, 41, 43-62.

Johnson, J. W. \& Ferstl, K. L. (1999). The effects of interrater and self-other agreement on performance improvement following upward feedback. Personnel Psychology, 52, 271-303.

Jones, E. E. \& Harris, V. (1967). The attribution of attitudes. Journal of Experimental Social Psychology, 3, 1-24.

Jones, E. E. \& Nisbett, R. E. (1971). The actor and the observer: Divergent perceptions of the cause of behavior. Morristown, NJ: General Learning Press.

Kenney, D. A. (1994). Interpersonal perception: A social relations analysis. New York, NY: Guilford Press.

Kernis, M. (1991). The roles of stability and level of selfesteem in psychological functioning. Institute of Behavioral Research, University of Georgia.

Klimoski, R. J. \& London, M. (1974). Role of the rater in performance appraisal. Journal of Applied Psychology, 59, 445-451.

Korman, A. K. (1970). Toward an hypothesis of work behavior. Journal of Applied Psychology, 54, 31-41.

Korman, A. K. (1976). Hypothesis of work behavior revisited and an extension. Academy of Management Review, 1, 50-63.

Landy, F. J. \& Farr, J. L. (1980). Performance ratings. Psychological Bulletin, 87, 72-107.

Leising, D., Rehbein, D., \& Sporberg, D. (2006). Does a fish see the water in which it swims? A study of the ability to correctly judge one's own interpersonal behavior. Journal of Social and Clinical Psychology, 25, 963-974.

Levine, E., Flory, A., \& Ash, R. (1977). Self-assessment in personnel selection. Journal of Applied Psychology, 62, 428-435.

McGivern, G. \& Ferlie, E. (2007). Playing tick-box games: Interrelating differences in professional appraisal. Human Relations, 60, 1361-1385.

Meleddu, M. \& Guicciardi, M. (1998). Self-knowledge and social desirability of personality traits. Journal of Personality, 12, 151-168.

Mount, M. K. (1998). Trait, rater, and level effects in 360degree performance ratings. Personnel Psychology, 51, 557-577. 
Murphy, K. R. \& DeShon, R. (2000). Interrater correlations do not estimate the reliability of job performance ratings. Personnel Psychology, 53, 873-900.

Paquet, S. L. (2005). A cultural look at performance appraisals: The role of individualism and collectivism in rating accuracy. An unpublished doctoral dissertation.

Roberts, T. (1991). Gender and influence of evaluations on self-assessments in achievement settings. Psychological Bulletin, 109, 297-308.

Regoli, B., Crank, J. P., \& Rivera, G. F. (1990). The construction and implementation of an alternative measure of police cynicism. Criminal Justice and Behavior, 17, 395409.

Roush, P. \& Atwater, L. (1992). Using the MBTI to understand transformational leadership and self-perception accuracy. Military Psychology, 4, 17-34.

Schlenker, B., Weingold, M., \& Hallam, J. (1990). Self-serving attributions in social context: Effects of self-esteem and social pressures. Journal of Personality and Social Psychology, 58, 855-863.

Schmitt, N., Ford, J. K., \& Stults, D. M. (1986). Changes in self-perceived ability as a function of performance in an assessment center. Journal of Occupational Psychology, 59, 327-335.

Sosik, J. J. \& Godshalk, V. M. (2004). Self-other rating agreement in mentoring: Meeting protégé expectations for development and career advancement. Group and Organization Management, 29, 442-469.

Sosik, J. J. \& Jung, D. I. (2002). Work-group characteristics and performance in collectivistic and individualistic cultures. Journal of Social Psychology, 142, 5-23.

Swann, W. (1983). Self-verification: Bringing social reality into harmony with the self. In J. Suls \& A. Greenwalt (Eds.), Psychological perspectives on the self (Vol. 2, pp. 33-66). Hillsdale, NJ: Lawrence Erlbaum.

Swann, W. \& Pelham, B. (1990). Embracing the bitter truth: Positivity and authenticity in social relationship. Unpublished manuscript, University of Texas, Austin.

Thornton, G. (1980). Psychometric properties of selfappraisal of job performance. Personnel Psychology, 33, 262-271
Treynor, W. F. (2004). Are the most mistrustful the least trustworthy? Studies of unethical behavior. An unpublished doctoral dissertation.

Van Hooft, E. A. J., Van der Flier, H., \& Minne, M. R. (2006). Construct validity of multi-source performance ratings: An examination of the relationship of self-, supervisor-, and peer-ratings with cognitive and personality measures. International Journal of Selection and Assessment, 14, 67-81.

Visser, B. A., Ashton, M. C., \& Vernon, P. A. (2008). What makes you think you're so smart? Measured abilities, personality and sex differences in relation to self-estimates of multiple intelligences. Journal of Individual Differences, 29, 35-44.

Viswesvaran, C. \& Ones, D. (1999). Meta-analyses of fakability estimates: Implications for personality measurement. Educational and Psychological Measurement, 59, 197-210.

Viswesvaran, C., Ones, D., \& Schmidt, F. (1996). Comparative analyses of the reliability of job performance ratings. Journal of Applied Psychology, 81, 557-574.

Waldman, D. A., Atwater, L. E., \& Davidson, R. A. (2004). The role of individualism and the Five-Factor Model in the prediction of performance in leaderless group discussion. Journal of Personality, 72, 1-28.

Wohlers, A. J. \& London, M. (1989). Rating of managerial characteristics: Evaluation difficulty, co-worker agreement, and self-awareness. Personnel Psychology, 42, 235-261.

Wymer, W. \& Penner, L. (1985). Moderator variables and different types of predictability: Do you have a match? Journal of Personality and Social Psychology, 49, 10021015.

Yammarino, F. J. \& Atwater, L. E. (1993). Understanding self-perception accuracy: Implications for human resource management. Human Resource Management, 32, 231-247.

Yammarino, F. J. \& Atwater, L. E. (1997). Do managers see themselves as others see them? Implications of self-other rating agreement for human resource management. Organizational Dynamics, 25, 35-44.

Manuscript Received: 08/09/2011

Revision Received: 21/01/2012 Accepted: 21/01/2012 